\title{
Association of XPC Gene Polymorphisms with Colorectal Cancer Risk in a Southern Chinese Population: A Case-Control Study and Meta-Analysis
}

\author{
Rui-Xi Hua ${ }^{1,2,+}$, Jinhong Zhu ${ }^{3,+}{ }^{+}$Dan-Hua Jiang ${ }^{4,+}$, Shao-Dan Zhang ${ }^{1}$, Jiang-Bo Zhang ${ }^{1}$, \\ Wen-Qiong Xue ${ }^{1}$, Xi-Zhao Li ${ }^{1}$, Pei-Fen Zhang ${ }^{1}$, Jing He ${ }^{1,5, *}$ and Wei-Hua Jia ${ }^{1, *}$ \\ 1 Sun Yat-sen University Cancer Center, State Key Laboratory of Oncology in South China, \\ Department of Experimental Research, Collaborative Innovation Center for Cancer Medicine, \\ Guangzhou 510060, Guangdong, China; mdhuarx@126.com (R.-X.H.); zhangshd@sysucc.org.cn (S.-D.Z.); \\ zhangjb@sysucc.org.cn (J.-B.Z.); xuewq@sysucc.org.cn (W.-Q.X.); lixzh@sysucc.org.cn (X.-Z.L.); \\ zhangpf@sysucc.org.cn (P.-F.Z.) \\ 2 Department of Oncology, The First Affiliated Hospital of Sun Yat-sen University, Guangzhou 510080, \\ Guangdong, China \\ 3 Molecular Epidemiology Laboratory and Department of Laboratory Medicine, \\ Harbin Medical University Cancer Hospital, Harbin 150040, Heilongjiang, China; \\ jinhongzhu625@gmail.com \\ 4 Department of Medical Genetics, Zhongshan School of Medicine, Sun Yat-sen University, \\ Guangzhou 510080, Guangdong, China; jiangdh5@163.com \\ 5 Department of Pediatric Surgery, Guangzhou Institute of Pediatrics, Guangzhou Women and Children's \\ Medical Center, Guangzhou Medical University, Guangzhou 510623, Guangdong, China \\ * Correspondence: hejing27@mail.sysu.edu.cn or hejing198374@gmail.com (J.H.); \\ jiaweih@mail.sysu.edu.cn (W.-H.J.); Tel.: +86-20-87342410 or +86-20-38076560 (J.H.); \\ +86-20-87342327 (W.-H.J.); Fax: +86-20-87343392 (W.-H.J.) \\ + These authors contributed equally to this work.
}

Academic Editor: Nora Nock

Received: 1 June 2016; Accepted: 16 September 2016; Published: 24 September 2016

\begin{abstract}
Xeroderma pigmentosum group C (XPC) is a key component of the nucleotide excision repair (NER) pathway. Dysfunctional XPC protein may impair NER-mediated DNA repair capacity and further lead to genomic instability and carcinogenesis. Two common nonsynonymous polymorphisms in the XPC gene, Lys939Gln (rs2228001 A > C) and Ala499Val (rs2228000 C > T), have been investigated in various types of cancer. We genotyped these two polymorphisms in 1141 cases with histologically confirmed colorectal cancer (CRC) and 1173 healthy controls to explore their causative association with CRC susceptibility. Overall, no association was observed between these two variants and the risk of CRC. Our meta-analysis also confirmed a lack of overall association. Stratified analyses were performed by age, gender, smoking status, pack-year, drinking status, tumor sites, and Duke's stages. We found that XPC Lys939Gln polymorphism was significantly associated with an increased CRC risk in subjects at 57 years of age or younger (adjusted odds ratio $(\mathrm{OR})=1.37,95 \%$ confidence interval $(\mathrm{CI})=1.004-1.86, p=0.047)$ and non-drinkers (adjusted $\mathrm{OR}=1.53$, $95 \% \mathrm{CI}=1.10-2.12, p=0.011$ ). Our results indicated that XPC Lys939Gln may be a low-penetrance CRC susceptibility polymorphism. Our findings warrant further validation.
\end{abstract}

Keywords: colorectal cancer; XPC; polymorphism; DNA repair; genetic susceptibility

\section{Introduction}

DNA damage constantly occurs because of the exposure to endogenous and exogenous mutagens. There are several DNA repair mechanisms that extensively eliminate genetic errors to maintain genome 
integrity, including base excision repair, mismatch repair, double-strand break repair, and nucleotide excision repair (NER). Among these DNA repair pathways, NER is in charge of repairing bulky DNA lesions, such as pyrimidine dimers, UV-induced DNA damage, chemical adducts, and crosslinks [1,2]. There are at least four critical steps involved in the NER pathway: (a) recognition of damaged DNA via a protein complex containing xeroderma pigmentosum group C (XPC); (b) uncoiling of DNA mediated by the transcription factor II human (TFIIH) complex; (c) excision of the damaged single-stranded fragment; (d) gap-filling DNA synthesis and DNA ligation [2,3].

XPC is an important protein in the NER pathway; it enables DNA repair by complexing with RAD23 homolog B (RAD23B) to facilitate the recognition of DNA damage and the initiation of DNA repair [4-6]. The detection of damaged DNA is the rate-limiting step in the NER pathway [5]. Therefore, the function of XPC is critical for proper DNA repair. Polymorphisms in the XPC gene may influence the function of the protein and an individual's DNA repair capacity, and thereby affect genetic instability and modify individual predisposition to cancer.

The XPC gene, located on chromosome 3p25, is highly polymorphic. To date, at least 102 single nucleotide polymorphisms (SNPs) have been reported in the coding region of this gene [7]. Of these coding region SNPs, XPC Lys939Gln (rs2228001 A > C) and Ala499Val (rs2228000 C > T) polymorphisms have been foci of interest for their potential function, as well as association with the risk of various types of cancer, including breast cancer, lung cancer, bladder cancer, and colorectal cancer (CRC) [8]. A number of studies have been conducted to explore the association between these two polymorphisms and CRC susceptibility in different ethnicities which have shown some promising results [9-11]. However, apart from one study with 1028 cases [12] and the current study (1141 cases), the number of cases in the included studies was relatively small, ranging from 133 to 665 . These studies might be limited by low statistical power; as a result, their conclusions might not be convincing. Moreover, such an association has not been evaluated in the southern Chinese population. With this in mind, we genotyped the two SNPs and assessed their association with CRC susceptibility in 1141 CRC cases and 1173 controls recruited from southern China.

\section{Results}

\subsection{Characteristics of Study Subjects}

We analyzed in total 1141 CRC cases and 1173 healthy controls in the present study (Table 1). There was no significant difference between cases and controls $(p=0.518)$ when compared by the matching factor, gender. However, cases were significantly older than controls (55.7 \pm 13.7 vs. $45.2 \pm 11.6)$. The percentage of ever smokers in cases $(27.3 \%)$ was significantly lower than that in controls (43.6\%). The pack-years also differed significantly between cases and controls. Moreover, there were significantly fewer drinkers in cases than in controls. In this study, 44.3\% (505) of cases had colon cancer, while $55.7 \%$ (636) had rectal cancer. In terms of the clinical stage, $130(11.4 \%), 363(31.8 \%)$, $359(31.5 \%)$, and $289(25.3 \%)$ patients were diagnosed with Duke's stage A, B, C, and D colorectal carcinoma, respectively.

Genotype frequency distributions of the two SNPs in controls were in agreement with the

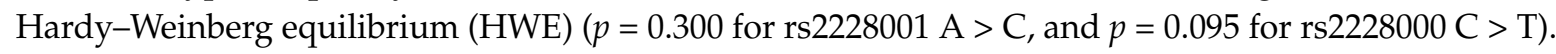
Overall, neither XPC Lys939Gln (rs2228001 A > C) nor Ala499Val (rs2228000 C > T) polymorphism was associated with the risk of CRC (Table 2). We next combined these two polymorphisms, which might increase the effect of individual polymorphisms and improve cancer risk prediction [13]. However, we found that carriers of one or two risk XPC genotypes had similar cancer risk to those carrying two wild-type genotypes (adjusted odds ratio $(\mathrm{OR})=1.13,95 \%$ confidence interval $(\mathrm{CI})=0.77-1.66$, $p=0.524$ for carriers of one risk genotype; adjusted $\mathrm{OR}=1.03,95 \% \mathrm{CI}=0.69-1.54, p=0.884$ for carriers of two risk genotypes) (Table 2). 
Table 1. Clinical and demographic characteristics of colorectal cancer patients and cancer-free controls.

\begin{tabular}{|c|c|c|c|}
\hline Variables & Cases No. (\%) & Controls No. $(\%)$ & $p^{\mathrm{a}}$ \\
\hline All subjects & $1141(100.0)$ & $1173(100.0)$ & \\
\hline \multicolumn{4}{|l|}{ Gender } \\
\hline Males & $753(66.0)$ & 789 (67.3) & \multirow[t]{3}{*}{0.518} \\
\hline Females & $388(34.0)$ & 384 (32.7) & \\
\hline Age, year & $13-89$ & $16-80$ & \\
\hline Mean b & $55.7 \pm 13.7$ & $45.2 \pm 11.6$ & \multirow[t]{5}{*}{$<0.0001$} \\
\hline$\leq 50$ & $367(32.2)$ & 789 (67.3) & \\
\hline $5 \overline{1}-60$ & $342(30.0)$ & $285(24.3)$ & \\
\hline $61-70$ & $273(23.9)$ & $73(6.2)$ & \\
\hline$>70$ & 159 (13.9) & $26(2.2)$ & \\
\hline \multicolumn{4}{|c|}{ Smoking status } \\
\hline Never & $830(72.7)$ & $662(56.4)$ & \multirow[t]{2}{*}{$<0.0001$} \\
\hline Ever & 311 (27.3) & $511(43.6)$ & \\
\hline \multicolumn{4}{|c|}{ Drinking status } \\
\hline No & 968 (84.8) & $600(51.2)$ & \multirow{2}{*}{$<0.0001$} \\
\hline Yes & $173(15.2)$ & $573(48.8)$ & \\
\hline \multicolumn{4}{|l|}{ Pack-years } \\
\hline 0 & 830 (72.7) & $662(56.4)$ & \multirow[t]{6}{*}{$<0.0001$} \\
\hline$\leq 30$ & 207 (18.1) & 383 (32.7) & \\
\hline$>30$ & $104(9.1)$ & $128(10.9)$ & \\
\hline Sites & & & \\
\hline Colon & $505(44.3)$ & - & \\
\hline Rectal & $636(55.7)$ & - & \\
\hline \multicolumn{4}{|l|}{ Duke Stages } \\
\hline A & 130 (11.4) & - & \\
\hline B & 363 (31.8) & - & \\
\hline C & 359 (31.5) & - & \\
\hline D & 289 (25.3) & - & \\
\hline
\end{tabular}

a Two-sided chi square test for distributions between colorectal cancer cases and cancer-free controls. ${ }^{\mathrm{b}}$ Data are mean \pm standard deviation.

Table 2. Associations between xeroderma pigmentosum group C (XPC) gene polymorphisms and colorectal cancer risk.

\begin{tabular}{|c|c|c|c|c|c|c|c|}
\hline Genotypes & Cases & Controls & $p^{\mathrm{a}}$ & OR $(95 \% \mathrm{CI})$ & $p$ & Adjusted OR (95\% CI) & $p^{\mathrm{b}}$ \\
\hline \multicolumn{8}{|c|}{ rs $2228001 \mathrm{~A}>\mathrm{C}$} \\
\hline AA & $476(41.7)$ & $472(40.2)$ & & 1.00 & & 1.00 & \\
\hline $\mathrm{AC}$ & 497 (43.6) & 557 (47.5) & & $0.89(0.74-1.06)$ & 0.172 & $0.92(0.76-1.13)$ & 0.667 \\
\hline $\mathrm{CC}$ & 168 (14.7) & 144 (12.3) & & $1.16(0.90-1.50)$ & 0.266 & $1.15(0.86-1.54)$ & 0.426 \\
\hline \multirow[t]{2}{*}{$\mathrm{AC} / \mathrm{CC}$} & $665(58.3)$ & 701 (59.8) & $0.470^{\mathrm{d}}$ & $0.94(0.80-1.11)$ & 0.470 & $0.97(0.80-1.17)$ & 0.752 \\
\hline & Additive model & & $0.089^{c}$ & $1.02(0.91-1.15)$ & 0.734 & $1.06(0.86-1.31)$ & 0.568 \\
\hline $\mathrm{AA} / \mathrm{AC}$ & $973(85.3)$ & 1029 (87.7) & & 1.00 & & 1.00 & \\
\hline $\mathrm{CC}$ & $168(14.7)$ & $144(12.3)$ & $0.085^{\mathrm{e}}$ & $1.23(0.97-1.57)$ & 0.086 & $1.20(0.92-1.58)$ & 0.188 \\
\hline \multicolumn{8}{|c|}{ rs2228000 C > T } \\
\hline $\mathrm{CC}$ & $432(37.9)$ & $429(36.6)$ & & 1.00 & & 1.00 & \\
\hline $\mathrm{CT}$ & $531(46.5)$ & 583 (49.7) & & $0.91(0.76-1.08)$ & 0.269 & $0.95(0.78-1.16)$ & 0.621 \\
\hline TT & $178(15.6)$ & $161(13.7)$ & & $1.10(0.85-1.41)$ & 0.467 & $1.11(0.83-1.47)$ & 0.485 \\
\hline \multirow{2}{*}{$\mathrm{CT} / \mathrm{TT}$} & $709(62.1)$ & 744 (63.4) & $0.521^{\mathrm{d}}$ & $0.95(0.80-1.12)$ & 0.521 & $0.99(0.81-1.19)$ & 0.878 \\
\hline & Additive model & & $0.241^{\mathrm{c}}$ & $1.01(0.90-1.14)$ & 0.837 & $1.03(0.90-1.18)$ & 0.688 \\
\hline $\mathrm{CC} / \mathrm{CT}$ & $963(84.4)$ & $1012(86.3)$ & & 1.00 & & 1.00 & \\
\hline TT & $178(15.6)$ & $161(13.7)$ & $0.202^{\mathrm{e}}$ & $1.16(0.92-1.46)$ & 0.203 & $1.14(0.88-1.48)$ & 0.327 \\
\hline \multicolumn{8}{|c|}{ Combined effect of XPC risk genotypes } \\
\hline 0 & $71(6.2)$ & $77(6.6)$ & & 1.00 & & 1.00 & \\
\hline 1 & $766(67.1)$ & 747 (63.7) & & $1.11(0.79-1.56)$ & 0.538 & $1.13(0.77-1.66)$ & 0.524 \\
\hline 2 & $304(26.6)$ & 349 (29.8) & 0.208 & $0.95(0.66-1.35)$ & 0.756 & $1.03(0.69-1.54)$ & 0.884 \\
\hline
\end{tabular}

$\mathrm{CI}$, confidence interval; OR, odds ratio. ${ }^{\text {a }} \mathrm{Chi}$ square test for genotype distributions between cases and controls;

${ }^{\mathrm{b}}$ Adjusted for age, gender, smoking and drinking status; ${ }^{\mathrm{c}}$ for additive genetic models; ${ }^{\mathrm{d}}$ for dominant genetic models; ${ }^{\mathrm{e}}$ for recessive genetic models. 


\subsection{Stratification Analysis}

We performed a stratified analysis by age, gender, smoking status, pack-year, drinking status, tumor sites, and Duke's stages (Table 3). A stratified analysis by age indicated that $X P C$ rs2228001 A > C polymorphism was significantly associated with an increased CRC risk in subjects at 57 years of age and younger (adjusted OR $=1.37,95 \% \mathrm{CI}=1.004-1.86, p=0.047$ ). A stratified analysis also revealed increased CRC risk associated with rs2228001 for never smokers $(\mathrm{OR}=1.42,95 \% \mathrm{CI}=1.05-1.92, p=0.024)$; however, the significance of the association disappeared after adjustment for age, gender, smoking and drinking status. Moreover, non-drinkers carrying rs2228001 AA/AC genotypes showed a significantly increased risk of CRC (adjusted OR $=1.53$, $95 \% \mathrm{CI}=1.10-2.12, p=0.011$ ), which was likely to be due to chance. In term of tumor sites, $X P C$ rs2228001 A > C did not seem to confer predisposition to either colon cancer or rectal cancer. XPC rs2228001 A > C polymorphism was not associated with Duke's stage, either. Moreover, no significant association with CRC risk was found for the rs2228000 C > T polymorphism in the stratified analysis.

\subsection{Meta-Analysis Results}

The two XPC polymorphisms have been frequently studied for their ability to modify CRC susceptibility. However, results remain open to more than one interpretation. We next carried out meta-analysis to further explore the association between these two polymorphisms and CRC risk by including eligible publications and our data (Preferred Reporting Items for Systematic Reviews and Meta-Analyses (PRISMA) flow diagram). Overall, there were 12 publications consisting of 13 studies (6107 cases and 8207 controls) for the rs2228001 A > C polymorphism and five publications consisting of six eligible studies (3533 cases and 4860 controls) for the rs2228000 C > T polymorphism (Table 4). After pooling all studies together, risk estimates indicated a lack of correlation between the rs 2228001 $\mathrm{A}>\mathrm{C}$ polymorphism and CRC risk (Table 5 and Figure 1). Similarly, null association with CRC risk was found for the rs2228000C $>\mathrm{T}$ polymorphism in overall and stratified analyses (Table 5 and Figure 2). 
Table 3. Stratification analysis for associations between the XPC rs2228001 A > C and rs2228000 C > T genotypes with colorectal cancer risk.

\begin{tabular}{|c|c|c|c|c|c|c|c|c|c|c|c|c|}
\hline \multirow[t]{2}{*}{ Variables } & \multicolumn{2}{|c|}{$\begin{array}{l}\text { rs2228001 A > C } \\
\text { (Cases/Controls) }\end{array}$} & \multirow[t]{2}{*}{ OR $(95 \% \mathrm{CI})$} & \multirow[t]{2}{*}{$p$} & \multirow{2}{*}{$\begin{array}{c}\text { Adjusted OR } \\
(95 \% \mathrm{CI})\end{array}$} & \multirow[t]{2}{*}{$p^{\mathrm{a}}$} & \multicolumn{2}{|c|}{$\begin{array}{l}\text { rs2228000 C > T } \\
\text { (Cases/Controls) }\end{array}$} & \multirow[t]{2}{*}{ OR $(95 \% \mathrm{CI})$} & \multirow[t]{2}{*}{$p$} & \multirow{2}{*}{$\begin{array}{c}\text { Adjusted OR } \\
(95 \% \text { CI })\end{array}$} & \multirow[t]{2}{*}{$p^{\mathrm{a}}$} \\
\hline & AA/AC & $\mathrm{CC}$ & & & & & CC/CT & TT & & & & \\
\hline \multicolumn{13}{|c|}{ Median age, years } \\
\hline$\leq 57$ & $501 / 874$ & $97 / 125$ & $1.35(1.02-1.80)$ & 0.039 & $\begin{array}{c}1.37 \\
(1.004-1.86)\end{array}$ & 0.047 & $500 / 865$ & $98 / 134$ & $1.27(0.95-1.68)$ & 0.103 & $1.20(0.89-1.62)$ & 0.236 \\
\hline$>57$ & $472 / 155$ & $71 / 19$ & $1.23(0.72-2.10)$ & 0.456 & $1.09(0.63-1.89)$ & 0.749 & $463 / 147$ & $80 / 27$ & $0.94(0.59-1.51)$ & 0.801 & $0.93(0.57-1.50)$ & 0.755 \\
\hline \multicolumn{13}{|l|}{ Gender } \\
\hline Males & $643 / 689$ & $110 / 100$ & $1.18(0.88-1.58)$ & 0.269 & $1.14(0.81-1.60)$ & 0.445 & $628 / 685$ & $125 / 104$ & $1.31(0.99-1.74)$ & 0.060 & $1.28(0.92-1.77)$ & 0.140 \\
\hline Females & $330 / 340$ & $58 / 44$ & $1.36(0.89-2.07)$ & 0.153 & $1.47(0.91-2.39)$ & 0.116 & $335 / 327$ & $53 / 57$ & $0.91(0.61-1.36)$ & 0.638 & $0.90(0.58-1.42)$ & 0.661 \\
\hline \multicolumn{13}{|c|}{ Smoking status } \\
\hline Never & $701 / 586$ & $129 / 76$ & $1.42(1.05-1.92)$ & 0.024 & $1.37(0.96-1.95)$ & 0.084 & $705 / 569$ & $125 / 93$ & $1.08(0.81-1.45)$ & 0.584 & $1.15(0.82-1.61)$ & 0.433 \\
\hline Ever & $272 / 443$ & $39 / 68$ & $0.93(0.61-1.43)$ & 0.753 & $1.03(0.65-1.64)$ & 0.898 & $258 / 443$ & $53 / 68$ & $1.34(0.91-1.98)$ & 0.144 & $1.16(0.75-1.81)$ & 0.501 \\
\hline \multicolumn{13}{|l|}{ Pack-year } \\
\hline 0 & $701 / 586$ & $129 / 76$ & $1.42(1.05-1.92)$ & 0.024 & $1.37(0.96-1.95)$ & 0.084 & $705 / 569$ & $125 / 93$ & $1.08(0.81-1.45)$ & 0.584 & $1.15(0.82-1.61)$ & 0.433 \\
\hline$\leq 30$ & $175 / 328$ & $32 / 55$ & $1.09(0.68-1.75)$ & 0.720 & $1.00(0.59-1.71)$ & 0.991 & $170 / 330$ & $37 / 53$ & $1.36(0.86-2.14)$ & 0.194 & $1.13(0.66-1.93)$ & 0.656 \\
\hline$>30$ & $97 / 115$ & $7 / 13$ & $0.64(0.25-1.66)$ & 0.358 & $0.87(0.32-2.38)$ & 0.791 & $88 / 113$ & $16 / 15$ & $1.37(0.64-2.92)$ & 0.416 & $1.18(0.53-2.62)$ & 0.681 \\
\hline \multicolumn{13}{|c|}{ Drinking status } \\
\hline Never & $813 / 533$ & $155 / 67$ & $1.52(1.12-2.06)$ & 0.008 & $1.53(1.10-2.12)$ & 0.011 & $818 / 512$ & $150 / 88$ & $1.07(0.80-1.42)$ & 0.658 & $1.09(0.81-1.48)$ & 0.575 \\
\hline Ever & $160 / 496$ & $13 / 77$ & $0.52(0.28-0.97)$ & 0.039 & $0.63(0.32-1.23)$ & 0.178 & $145 / 500$ & $28 / 73$ & $1.32(0.82-2.12)$ & 0.247 & $1.48(0.84-2.61)$ & 0.175 \\
\hline \multicolumn{13}{|l|}{ Tumor sites } \\
\hline Colon & $431 / 1209$ & $74 / 144$ & $1.23(0.91-1.66)$ & 0.185 & $1.31(0.93-1.85)$ & 0.124 & $429 / 1012$ & $76 / 161$ & $1.11(0.83-1.50)$ & 0.475 & $1.12(0.80-1.57)$ & 0.497 \\
\hline Rectal & $542 / 1209$ & $94 / 144$ & $1.24(0.94-1.64)$ & 0.133 & $1.15(0.84-1.58)$ & 0.377 & $534 / 1012$ & $102 / 161$ & $1.20(0.92-1.57)$ & 0.183 & $1.14(0.84-1.54)$ & 0.394 \\
\hline \multicolumn{13}{|l|}{ Duke stages } \\
\hline$A+B$ & $425 / 1209$ & $68 / 144$ & $1.14(0.84-1.56)$ & 0.397 & $1.10(0.77-1.58)$ & 0.593 & $421 / 1012$ & $72 / 161$ & $1.08(0.80-1.45)$ & 0.637 & $1.09(0.77-1.54)$ & 0.644 \\
\hline$C+D$ & $548 / 1209$ & $100 / 144$ & $1.30(0.99-1.72)$ & 0.059 & $1.31(0.97-1.79)$ & 0.083 & $542 / 1012$ & $106 / 161$ & $1.23(0.94-1.61)$ & 0.129 & $1.18(0.88-1.59)$ & 0.272 \\
\hline
\end{tabular}


Table 4. Characteristics of available studies included in the current meta-analysis.

\begin{tabular}{|c|c|c|c|c|c|c|c|c|c|c|c|c|c|c|c|}
\hline \multirow{2}{*}{$\frac{\text { Study }}{\text { rs2228001 A >C }}$} & \multirow[t]{2}{*}{ Year } & \multirow[t]{2}{*}{ Country } & \multirow[t]{2}{*}{ Ethnicity } & \multirow[t]{2}{*}{ Source } & \multirow[t]{2}{*}{ Genotyping } & \multicolumn{4}{|c|}{ Number of Cases } & \multicolumn{4}{|c|}{ Number of Controls } & \multirow[t]{2}{*}{ MAF } & \multirow[t]{2}{*}{ HWE } \\
\hline & & & & & & All & AA & $\mathrm{AC}$ & $\mathrm{CC}$ & All & $\mathrm{AA}$ & $\mathrm{AC}$ & $\mathrm{CC}$ & & \\
\hline Huang & 2006 & USA & Caucasian & PB & TaqMan & 665 & 253 & 300 & 112 & 667 & 241 & 312 & 114 & 0.40 & 0.450 \\
\hline Hansen & 2007 & Denmark & Caucasian & PB & TaqMan & 395 & 141 & 204 & 50 & 797 & 307 & 392 & 98 & 0.37 & 0.112 \\
\hline Pardini & 2008 & Czech & Caucasian & HB & PCR-RFLP & 532 & 171 & 268 & 93 & 532 & 189 & 243 & 100 & 0.42 & 0.165 \\
\hline Engin & 2010 & Turkey & Caucasian & HB & PCR-RFLP & 110 & 22 & 63 & 25 & 116 & 25 & 55 & 36 & 0.55 & 0.642 \\
\hline $\mathrm{Wu}$ & 2011 & China & Asian & PB & PCR-RFLP & 420 & 155 & 204 & 61 & 842 & 363 & 375 & 104 & 0.35 & 0.639 \\
\hline Gil & 2012 & Poland & Caucasian & $\mathrm{HB}$ & PCR-RFLP & 133 & 48 & 71 & 14 & 100 & 43 & 46 & 11 & 0.34 & 0.803 \\
\hline Liu & 2012 & China & Asian & PB & TaqMan & 1028 & 360 & 565 & 103 & 1085 & 453 & 500 & 132 & 0.35 & 0.740 \\
\hline Yue & 2013 & China & Asian & $\mathrm{HB}$ & PCR-RFLP & 428 & 142 & 225 & 61 & 450 & 174 & 212 & 64 & 0.38 & 0.964 \\
\hline Ahmad Aizat & 2013 & Malaysia & Asian & HB & PCR-RFLP & 255 & 108 & 106 & 41 & 255 & 129 & 100 & 26 & 0.30 & 0.316 \\
\hline Steck & 2014 & USA & Caucasian & PB & MassARRAY & 303 & 103 & 148 & 52 & 532 & 191 & 252 & 89 & 0.40 & 0.704 \\
\hline Steck & 2014 & USA & African & PB & MassARRAY & 226 & 126 & 91 & 9 & 322 & 149 & 142 & 31 & 0.32 & 0.736 \\
\hline Paszkowska-Szczur & 2015 & Poland & Caucasian & $\mathrm{PB}$ & TaqMan & 471 & 187 & 202 & 82 & 1336 & 480 & 647 & 209 & 0.40 & 0.711 \\
\hline Hua & Current & China & Asian & PB & TaqMan & 1141 & 476 & 497 & 168 & 1173 & 472 & 557 & 144 & 0.36 & 0.300 \\
\hline rs2228000 C > T & & & & & & All & $\mathrm{CC}$ & $\mathrm{CT}$ & $\mathrm{TT}$ & All & $\mathrm{CC}$ & $\mathrm{CT}$ & $\mathrm{TT}$ & & \\
\hline Huang & 2006 & USA & Caucasian & PB & TaqMan & 689 & 397 & 261 & 31 & 703 & 403 & 259 & 41 & 0.24 & 0.942 \\
\hline $\mathrm{Wu}$ & 2011 & China & Asian & PB & PCR-RFLP & 419 & 172 & 195 & 52 & 838 & 315 & 406 & 117 & 0.38 & 0.447 \\
\hline Steck & 2014 & USA & Caucasian & PB & MassARRAY & 303 & 177 & 104 & 22 & 535 & 293 & 207 & 35 & 0.26 & 0.847 \\
\hline Steck & 2014 & USA & African & PB & MassARRAY & 228 & 175 & 51 & 2 & 323 & 276 & 47 & 0 & 0.07 & 0.158 \\
\hline Paszkowska-Szczur & 2015 & Poland & Caucasian & PB & TaqMan & 753 & 443 & 269 & 41 & 1288 & 548 & 563 & 177 & 0.36 & 0.094 \\
\hline Hua & Current & China & Asian & PB & TaqMan & 1141 & 432 & 531 & 178 & 1173 & 429 & 583 & 161 & 0.39 & 0.095 \\
\hline
\end{tabular}

$\mathrm{HB}$, hospital based; $\mathrm{PB}$, population based; PCR-RFLP, polymerase chain reaction-restriction fragment length polymorphism; MAF, minor allele frequency; HWE, Hardy-Weinberg equilibrium. 
Table 5. Meta-analysis of the association between XPC rs2228001 A >C and rs2228001 C > T polymorphisms and colorectal cancer risk.

\begin{tabular}{|c|c|c|c|c|c|c|c|c|c|c|c|}
\hline \multirow[t]{2}{*}{ Variables } & \multirow{2}{*}{$\begin{array}{l}\text { No. of } \\
\text { Studies }\end{array}$} & \multicolumn{2}{|c|}{ Homozygous } & \multicolumn{2}{|c|}{ Heterozygous } & \multicolumn{2}{|c|}{ Recessive } & \multicolumn{2}{|c|}{ Dominant } & \multicolumn{2}{|c|}{ Allele Comparison } \\
\hline & & OR $(95 \% \mathrm{CI})$ & $p^{\text {het }}$ & OR $(95 \% \mathrm{CI})$ & $p^{\text {het }}$ & OR $(95 \% \mathrm{CI})$ & $p^{\text {het }}$ & OR $(95 \% \mathrm{CI})$ & $p^{\text {het }}$ & OR $(95 \% \mathrm{CI})$ & $p^{\text {het }}$ \\
\hline \multicolumn{2}{|c|}{$\mathrm{rs} 2228001 \mathrm{~A}>\mathrm{C}$} & \multicolumn{2}{|c|}{ CC vs. AA } & \multicolumn{2}{|c|}{ AC vs. AA } & \multicolumn{2}{|c|}{ CC vs. $(A C+A A)$} & \multicolumn{2}{|c|}{$(\mathrm{AC}+\mathrm{CC})$ vs. $\mathrm{AA}$} & \multirow{2}{*}{\multicolumn{2}{|c|}{$\begin{array}{r}\text { C vs. A } \\
1.04(0.97-1.12)\end{array}$}} \\
\hline All & 13 & $1.07(0.96-1.19)$ & 0.175 & $1.09(0.96-1.24)$ & 0.002 & $1.01(0.89-1.15)$ & 0.083 & $1.08(0.97-1.21)$ & 0.005 & & 0.050 \\
\hline \multicolumn{12}{|l|}{ Ethnicity } \\
\hline Caucasian & 7 & $1.01(0.87-1.18)$ & 0.984 & $1.04(0.90-1.20)$ & 0.169 & $0.99(0.87-1.14)$ & 0.789 & $1.02(0.91-1.14)$ & 0.384 & $1.01(0.94-1.08)$ & 0.851 \\
\hline Asian & 5 & $1.18(1.02-1.38)$ & 0.294 & $1.20(0.98-1.48)$ & 0.004 & $1.11(0.89-1.39)$ & 0.061 & $1.21(1.03-1.43)$ & 0.030 & $1.12(1.03-1.21)$ & 0.266 \\
\hline African & 1 & $0.34(0.16-0.75)$ & / & $0.76(0.53-1.08)$ & / & $0.39(0.18-0.84)$ & / & $0.68(0.49-0.96)$ & / & $0.69(0.52-0.90)$ & I \\
\hline \multicolumn{12}{|c|}{ Source of control } \\
\hline PB & 8 & $1.04(0.92-1.17)$ & 0.122 & $1.02(0.87-1.20)$ & $<0.001$ & $1.01(0.87-1.19)$ & 0.072 & $1.02(0.88-1.18)$ & 0.002 & $1.02(0.94-1.11)$ & 0.040 \\
\hline $\mathrm{HB}$ & 5 & $1.16(0.93-1.45)$ & 0.358 & $1.27(1.08-1.49)$ & 0.995 & $1.00(0.77-1.30)$ & 0.193 & $1.25(1.07-1.45)$ & 0.924 & $1.11(0.99-1.25)$ & 0.315 \\
\hline \multicolumn{2}{|c|}{$\mathrm{rs} 2228000 \mathrm{C}>\mathrm{T}$} & \multicolumn{2}{|c|}{$\begin{array}{c}1.16(0.93-1.45) \\
\text { TT vs. CC }\end{array}$} & \multicolumn{2}{|c|}{ CT vs. CC } & \multicolumn{2}{|c|}{ TT vs. $(C T+C C)$} & \multicolumn{2}{|c|}{ (CT + TT) vs. CC } & \multirow{2}{*}{$\begin{array}{r}\text { T vs. C } \\
0.93(0.72-1.19)\end{array}$} & \\
\hline All & 6 & $0.77(0.46-1.31)$ & $<0.001$ & $0.91(0.72-1.14)$ & $<0.001$ & $0.83(0.52-1.30)$ & $<0.001$ & $0.90(0.69-1.19)$ & $<0.001$ & & $<0.001$ \\
\hline \multicolumn{12}{|l|}{ Ethnicity } \\
\hline Caucasian & 3 & $0.60(0.26-1.36)$ & $<0.001$ & $0.79(0.56-1.13)$ & 0.001 & $0.66(0.33-1.31)$ & 0.001 & $0.76(0.49-1.17)$ & $<0.001$ & $0.78(0.53-1.15)$ & $<0.001$ \\
\hline Asian & 2 & $0.98(0.74-1.30)$ & 0.195 & $0.90(0.78-1.04)$ & 0.860 & $1.04(0.79-1.37)$ & 0.182 & $0.92(0.80-1.05)$ & 0.547 & $0.97(0.87-1.09)$ & 0.261 \\
\hline African & 1 & $7.88(0.38-165.05)$ & / & $1.71(1.10-2.66)$ & / & $7.14(0.34-149.46)$ & I & $1.78(1.15-2.75)$ & I & $1.75(1.16-2.63)$ & / \\
\hline \multicolumn{12}{|c|}{ Source of control } \\
\hline $\mathrm{PB}$ & 6 & $0.77(0.46-1.31)$ & $<0.001$ & $0.91(0.72-1.14)$ & $<0.001$ & $0.83(0.52-1.30)$ & $<0.001$ & $0.90(0.69-1.19)$ & $<0.001$ & $0.93(0.72-1.19)$ & $<0.001$ \\
\hline
\end{tabular}

OR, odds ratio; $\mathrm{CI}$, confidence interval; $\mathrm{HB}$, hospital based; $\mathrm{PB}$, population based. 


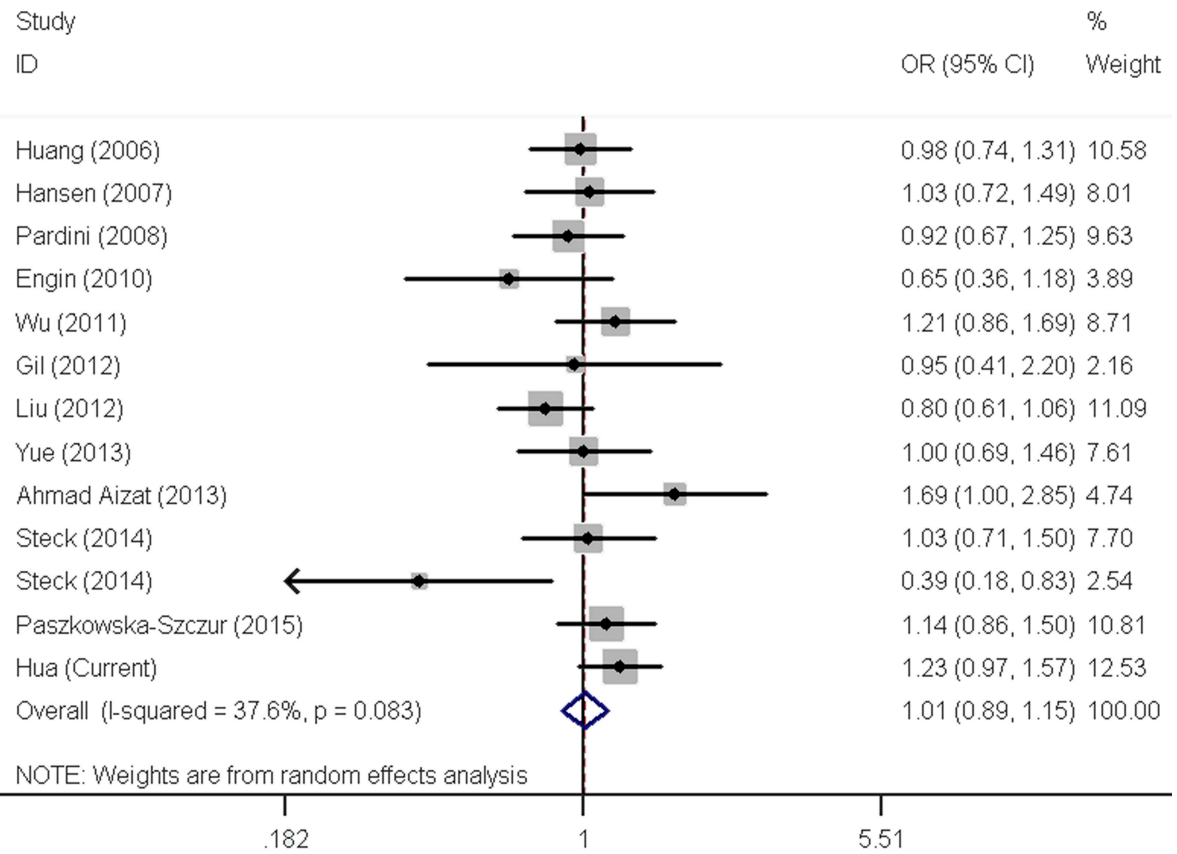

Figure 1. Forest plot of effect estimates for xeroderma pigmentosum group C (XPC) rs2228001 A > C polymorphism with overall colorectal cancer risk by a recessive model. For each study, the estimates of odds ratio (OR) and its $95 \%$ confidence interval (CI) are plotted with a box and a horizontal line. $\checkmark$, pooled ORs and its $95 \%$ CIs.

Study

ID

Huang (2006)

Wu (2011)

Steck (2014)

Steck (2014)

Paszkowska-Szczur (2015)

Hua (Current)

Overall (I-squared $=84.8 \%, p=0.000)$

NOTE: Weights are from random effects analysis

.00669
$\%$

$\mathrm{OR}(95 \% \mathrm{Cl}) \quad$ Weight

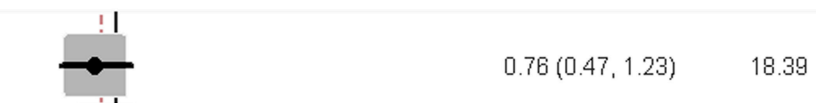

$0.87(0.62,1.24) \quad 20.30$

$1.12(0.64,1.94) \quad 17.23$

$7.14(0.34,149.46) \quad 2.06$

$0.36(0.25,0.51) \quad 20.26$

$1.16(0.92,1.46) \quad 21.76$

$0.83(0.52 .1 .30) \quad 100.00$

Figure 2. Forest plot of effect estimates for XPC rs2228000 C > T polymorphism with overall colorectal cancer risk by a recessive model. For each study, the estimates of OR and its 95\% CI are plotted with a box and a horizontal line. $\diamond$, pooled ORs and its $95 \%$ CIs.

\section{Discussion}

The association between two common nonsynonymous XPC polymorphisms (rs2228001 A > C and rs2228000 C > T) and the risk of CRC was evaluated in 1141 CRC cases and 1173 healthy controls 
enrolled from southern China. We found no statistical evidence of a significant association between these two polymorphisms and the risk of CRC. A combined analysis with these two polymorphisms suggested that subjects carrying one or two risk genotypes did not show increased CRC risk, when compared with non-carriers. Stratified analyses by age, gender, smoking status, pack-year, drinking status, tumor sites, and Duke's stages demonstrated a significant association between the XPC rs2228001 variant allele and increased CRC risk in participants at 57 years of age or under, non-smokers, and non-drinkers. However, in the stratified analysis, age, smoking status, and drinking status had no effect on the association between the rs2228000 C > T polymorphism and the risk of CRC. The role of the XPC gene in carcinogenesis started to attract attention because of the observation that mutations in the DNA repair genes can cause the inherited disease xeroderma pigmentosum (XP). This disease is characterized by hypersensitivity to UV light due to impaired DNA repair capacity. XP patients have an approximately 1000-fold higher risk of developing multiple skin cancers [14]. XPC participates in NER by recognizing specific changes in the DNA structures, instead of the lesions themselves [15]. Upon recognition of damaged DNA, the XPC complex can interact with xeroderma pigmentosum group A (XPA) or TFIIH to enable the downstream steps of NER, including excision and restoration of DNA [16]. There are three widely investigated common polymorphisms in the XPC gene, $X P C$ rs2228001 A > C, rs2228000 C > T [8], and a poly (AT) deletion/insertion on intron 9 [17]. The XPC rs2228001 A > C polymorphism, an A-to-C transition in exon 15, leads to a substitution of glutamine for lysine in codon 939 (Lys939Gln), while rs $2228000 \mathrm{C}>\mathrm{T}$ polymorphism is a C-to-T transition in exon 8, resulting in the replacement of alanine with valine in codon 499 (Ala499Val) [18]. The XPC rs2228001 A > C polymorphism is located in the domain interacting with TFIIH. Both biological and biochemical evidence showed that XPC rs2228001 A > C polymorphism could alter the DNA repair capacity $[19,20]$. Moreover, lymphocytes from individuals with this XPC polymorphism were shown to have a reduced capacity of repairing benzo(a)pyrene DNA adducts [21].

Our findings were in line with some previous studies. A number of case-control studies have been carried out to investigate the association between XPC rs2228001 A > C polymorphism and the risk of CRC among Caucasians [22-28]. Despite biological plausibility, none of those investigations provided evidence of the association of this polymorphism with CRC susceptibility [22-28]. Several studies have also evaluated the role of XPC rs2228001 A > C polymorphism in CRC among Asians [11,12,29,30]. Wu et al. [29] reported that carriers of the CC genotype had a significantly increased risk of CRC in an eastern Chinese population with 421 CRC patients and 845 controls. Liu et al. [12] assessed the association in a northeastern Chinese population including 1028 CRC cases and 1085 controls. They found that the XPC rs2228001 A > C polymorphism was significantly associated with increased CRC risk under the heterozygous ( $\mathrm{OR}=1.40,95 \% \mathrm{CI}=1.16-1.69)$ and dominant $(\mathrm{OR}=1.31,95 \% \mathrm{CI}=1.10-1.56, p=0.001)$ genetic models. In contrast, Yue et al. [30] failed to repeat the reported association in Chinese patients in a study population of 428 CRC cases and 450 controls. The conflicting results regarding the association from different studies might be, in part, attributed to the variations in samplings, sample sizes, genotyping methods, genetic backgrounds, and ethnicities. It was also worth noting that we identified XPC rs2228001 A > C polymorphism as a CRC susceptibility variant in some subpopulations, including participants at 57 years of age and under, non-smokers, and non-drinkers, but these findings could lack causality. Taken together, these findings suggest that XPC rs2228001 A > C polymorphism may be a low-penetrance common polymorphism with a moderate effect on CRC susceptibility. Large, well-designed multicenter studies, with consideration of epidemiological characteristics and lifestyles, should be performed to clarify the role of XPC rs2228001 A > C polymorphism in CRC carcinogenesis.

When compared with the XPC rs2228001 A > C polymorphism, relatively fewer studies have examined the association of the rs $2228000 \mathrm{C}>\mathrm{T}$ polymorphism with CRC susceptibility $[25,27-29]$. The results from three studies were similar to ours [25,28,29]. Interestingly, Steck et al. [28] reported a significantly positive association between this polymorphism and CRC risk in African Americans, while another study demonstrated an association in the reverse direction in Caucasians [27]. 
Several meta-analyses on the association between these two polymorphisms and CRC risk have been published $[8,10,31]$. Since then, many relevant studies have been reported. Therefore, we also performed a meta-analysis to reevaluate the association of interest, with the addition of more studies. To date, the current meta-analysis was the largest pooled study on this topic and showed null association for these two polymorphisms.

Replication study is the golden method for the validation of the genetic associations. We tested the association of interest in the study with a relatively large sample size. As a result, the statistical power was largely increased in comparison with previous studies and the results were convincing. In the present study, the statistical power to detect a significant finding in younger subjects, never smokers, and never drinkers was $77.2 \%, 65.4 \%$, and $47.9 \%$, respectively. While using our sample size, the statistical power to detect the OR of 1.20 was approximately $70 \%$ in a recessive genetic model. Therefore, this study was important in defining genetic susceptibility to CRC. Given that the genetic backgrounds of populations may vary depending on regions and ethnicities, findings from other regions and races may not be applicable to the southern Chinese population. This study was the first one to evaluate the association in the southern Chinese population. Moreover, single case-control studies often yield conflicting results, partially due to the relatively small sample sizes of each study and variations in samplings, ethnicities, genotyping methods, and study designs (e.g., population-based vs. hospital-based) among studies. To overcome these drawbacks, we also conducted a meta-analysis on the associations of interest by pooling all eligible studies and ours together. The meta-analysis results verified our findings from the current case-control study.

However, several limitations of the studies were deserving of attention. First, the present study only had a moderate sample size. Especially, the sample size in the stratified analysis was even smaller and for this reason the statistical power might be limited. Second, we only analyzed two potentially functional polymorphisms in the XPC gene. More potentially functional polymorphisms in the XPC gene should be studied. Third, details on other risk factors, including lack of exercise, being overweight or obese, and high consumption of red meat, were not available for cases and controls, which prevented us from further investigating the effects of these parameters on the association. Fourth, the current study was a gender matched case-control study; age and other factors, such as smoking and drinking status, were not factored into the study design, which might lead to a selection bias. Fifth, an information collection bias might exist. For example, the cases had a lower percentage of individuals with a history of smoking or alcohol consumption than controls did in our current study. Sixth, $32.2 \%$ of the cases with colorectal cancer were 50 years of age or younger, which was a little higher than that (21.9\%) in previous investigations performed in central China [32]. This discrepancy may be ascribed to geographical diversities. Moreover, some of our cases might have a family history of cancer. Finally, future in vitro and in vivo studies are needed to further provide biological evidence of the risk effects of XPC rs2228001 A > C polymorphism on the development of CRC and clarify the underlying mechanisms.

In conclusion, we did not find any predominant effects of the XPC rs2228001 A > C and rs2228000 C > T polymorphisms with CRC risk in the southern Chinese population. Our findings should be interpreted cautiously and warrant further validation in prospective investigations.

\section{Materials and Methods}

\subsection{Study Population}

We recruited 1141 cases with histologically confirmed CRC between January 2000 and May 2010 in Sun Yat-sen University Cancer Center. Patients with primary cancer in sites other than the colon and rectum were removed from the final study. Moreover, 1173 healthy residents in the same region were randomly recruited as controls in the same period of time, and they were frequency-matched to cases on gender. All the participants were of the ethnic Han Chinese population from southern China and genetically unrelated. Potential participants were contacted to screen for eligibility and the 
written informed consent was signed by each of the study subjects. A self-administered questionnaire was employed to collect information from individuals during a personal interview by their attending doctors, including demographic characteristics (age and gender), lifestyle (e.g., smoking habits and alcohol consumption), and family history of cancer. A blood sample of approximately $5 \mathrm{~mL}$ was obtained from each subject at the end of the interview. Overall, more than $80 \%$ of cases and controls responded. This investigation was approved by the institutional review board of Sun Yat-sen University Cancer Center (Guangzhou, China). Written informed consent was obtained from all patients.

\subsection{Genotyping}

Genotyping procedures were described elsewhere [33-35]. Briefly, genomic DNA was isolated from peripheral blood samples using the Qiagen Blood DNA Mini Kit (Qiagen Inc., Valencia, CA, USA). The Taqman method was chosen for genotyping these two polymorphisms with a 7900 HT sequence detector system (Applied Biosystems, Foster City, CA, USA). Quality control was strictly conducted, with four duplicate positive controls and four negative controls (omitting the DNA template) loaded in each of 384-well plates. Moreover, genotyping assays were repeated with $10 \%$ of the samples that were randomly selected and genotyping results were $100 \%$ concordant. Laboratory staff were blind to the case/control status of the samples.

\subsection{Statistical Analysis}

We performed Pearson's $\chi^{2}$ test and the Student's $t$ test to compare categorical variables and continuous variables between cases and controls, respectively. A goodness-of-fit $\chi^{2}$ test was used to check the significant deviation of SNP genotype frequencies from HWE in the control subjects. An unconditional logistic regression analysis was conducted to calculate ORs and 95\% CIs. An additional adjustment for age, gender, smoking and drinking status was made in the multivariate logistic regression analysis. We also carried out a stratified analysis by age, gender, pack-years, smoking and drinking status to study whether these factors could modify the association of interest. All analyses were performed using SAS software (Version 9.1; SAS Institute, Cary, NC, USA). All tests were two-sided. Results were considered statistically significant at $p<0.05$.

\subsection{Meta-Analysis}

The meta-analyses were conducted on the association between the two SNPs (rs2228001 A > $\mathrm{C}$ and rs2228000 C > T) and CRC susceptibility following the PRISMA checklist [36]. Systematic literature searches of MEDLINE, EMBASE, and PubMed databases were conducted. The search terms were as follows: "Xeroderma pigmentosum group C or XPC", "Lys939Gln or rs2228001", "Ala499Val or rs2228000", "polymorphism or variant or variation", and "colorectal cancer or tumor or carcinoma or neoplasm or CRC". Literature searches were performed between October and November 2015. Detailed procedures referred to previous publications [8,37-40]. Cross-study heterogeneity was determined by a chi-square-based $Q$-Test. The fixed-effects model (the Mantel-Haenszel method) [12] or the random-effects model (the DerSimonian and Laird method) [13] would be performed in the absence or presence of heterogeneity, respectively. Publication bias was measured by the funnel plot and the Egger's linear regression test [14]. Furthermore, a sensitivity analysis was also performed. We performed all analyses using STATA version 11.0 (StataCorporation, College Station, TX, USA).

Acknowledgments: This study was supported by grants from the National Natural Science Foundation of China (Grant No. 81502046), Special Financial Grant from the China Postdoctoral Science Foundation (Grant No. 2014T70836), the Natural Science Foundation of Guangdong Province (Grant No. 2015A030310324), and the National Science Fund for Distinguished Young Scholars (Grant No. 81325018).

Author Contributions: Rui-Xi Hua and Jinhong Zhu analyzed the data. Rui-Xi Hua, Jinhong Zhu and Jing He wrote the paper. Dan-Hua Jiang, Shao-Dan Zhang, Jiang-Bo Zhang, Wen-Qiong Xue, Xi-Zhao Li, and Pei-Fen Zhang performed the research study and collected the data. Rui-Xi Hua and Jing He prepared all the tables and figures. Jing He and Wei-Hua Jia conceived and designed the experiments. All authors read and approved the final manuscript. 
Conflicts of Interest: The authors declare no conflict of interest.

\section{References}

1. De Silva, I.U.; McHugh, P.J.; Clingen, P.H.; Hartley, J.A. Defining the roles of nucleotide excision repair and recombination in the repair of DNA interstrand cross-links in mammalian cells. Mol. Cell. Biol. 2000, 20, 7980-7990. [CrossRef] [PubMed]

2. Friedberg, E.C. How nucleotide excision repair protects against cancer. Nat. Rev. Cancer 2001, 1, $22-33$. [CrossRef] [PubMed]

3. Christmann, M.; Tomicic, M.T.; Roos, W.P.; Kaina, B. Mechanisms of human DNA repair: An update. Toxicology 2003, 193, 3-34. [CrossRef]

4. Sugasawa, K.; Ng, J.M.; Masutani, C.; Iwai, S.; van der Spek, P.J.; Eker, A.P.; Hanaoka, F.; Bootsma, D.; Hoeijmakers, J.H. Xeroderma pigmentosum group C protein complex is the initiator of global genome nucleotide excision repair. Mol. Cell 1998, 2, 223-232. [CrossRef]

5. Thoma, B.S.; Vasquez, K.M. Critical DNA damage recognition functions of XPC-hHR23B and XPA-RPA in nucleotide excision repair. Mol. Carcinog. 2003, 38, 1-13. [CrossRef] [PubMed]

6. Wood, R.D. DNA damage recognition during nucleotide excision repair in mammalian cells. Biochimie 1999, 81, 39-44. [CrossRef]

7. NCBI. dbSNP: Short Genetic Variations. Available online: http://www.ncbi.nlm.nih.gov/projects/SNP (accessed on 26 August 2016).

8. He, J.; Shi, T.Y.; Zhu, M.L.; Wang, M.Y.; Li, Q.X.; Wei, Q.Y. Associations of Lys939Gln and Ala499Val polymorphisms of the XPC gene with cancer susceptibility: A meta-analysis. Int. J. Cancer 2013, 133, 1765-1775. [CrossRef] [PubMed]

9. Liu, C.; Yin, Q.; Ying, M.; Lin, J.; Li, L.; Jiao, G.; Wang, M.; Wang, Y. XPC Lys939Gln and Ala499Val polymorphisms in colorectal cancer susceptibility: A meta-analysis of case-control studies. Mol. Biol. Rep. 2014, 41, 1171-1178. [CrossRef] [PubMed]

10. Peng, Q.; Lao, X.; Tang, W.; Chen, Z.; Li, R.; Qin, X.; Li, S. XPC Lys939Gln polymorphism contributes to colorectal cancer susceptibility: Evidence from a meta-analysis. Diagn. Pathol. 2014, 9, 120. [CrossRef] [PubMed]

11. Ahmad Aizat, A.A.; Siti Nurfatimah, M.S.; Aminudin, M.M.; Ankathil, R. XPC Lys939Gln polymorphism, smoking and risk of sporadic colorectal cancer among Malaysians. World J. Gastroenterol. 2013, 19, 3623-3628. [CrossRef] [PubMed]

12. Liu, D.; Wu, H.Z.; Zhang, Y.N.; Kang, H.; Sun, M.J.; Wang, E.H.; Yang, X.L.; Lian, M.Q.; Yu, Z.J.; Zhao, L.; et al. DNA repair genes XPC, XPG polymorphisms: Relation to the risk of colorectal carcinoma and therapeutic outcome with oxaliplatin-based adjuvant chemotherapy. Mol. Carcinog. 2012, 51 (Suppl. 1), E83-E93. [CrossRef] [PubMed]

13. Wu, X.; Gu, J.; Grossman, H.B.; Amos, C.I.; Etzel, C.; Huang, M.; Zhang, Q.; Millikan, R.E.; Lerner, S.; Dinney, C.P.; et al. Bladder cancer predisposition: A multigenic approach to DNA-repair and cell-cycle-control genes. Am. J. Hum. Genet. 2006, 78, 464-479. [CrossRef] [PubMed]

14. Saladi, R.N.; Persaud, A.N. The causes of skin cancer: A comprehensive review. Drugs Today 2005, 41, 37-53. [CrossRef] [PubMed]

15. Sugasawa, K.; Shimizu, Y.; Iwai, S.; Hanaoka, F. A molecular mechanism for DNA damage recognition by the xeroderma pigmentosum group C protein complex. DNA Repair 2002, 1, 95-107. [CrossRef]

16. Costa, R.M.; Chigancas, V.; Galhardo Rda, S.; Carvalho, H.; Menck, C.F. The eukaryotic nucleotide excision repair pathway. Biochimie 2003, 85, 1083-1099. [CrossRef] [PubMed]

17. Dai, Q.S.; Hua, R.X.; Zhang, R.; Huang, Y.S.; Hua, Z.M.; Yun, C.T.; Zeng, R.F.; Long, J.T. Poly (AT) deletion/insertion polymorphism of the XPC gene contributes to urinary system cancer susceptibility: A meta-analysis. Gene 2013, 528, 335-342. [CrossRef] [PubMed]

18. Francisco, G.; Menezes, P.R.; Eluf-Neto, J.; Chammas, R. XPC polymorphisms play a role in tissue-specific carcinogenesis: A meta-analysis. Eur. J. Hum. Genet. 2008, 16, 724-734. [CrossRef] [PubMed]

19. Qiao, Y.; Spitz, M.R.; Shen, H.; Guo, Z.; Shete, S.; Hedayati, M.; Grossman, L.; Mohrenweiser, H.; Wei, Q. Modulation of repair of ultraviolet damage in the host-cell reactivation assay by polymorphic XPC and XPD/ERCC2 genotypes. Carcinogenesis 2002, 23, 295-299. [CrossRef] [PubMed] 
20. Naccarati, A.; Soucek, P.; Stetina, R.; Haufroid, V.; Kumar, R.; Vodickova, L.; Trtkova, K.; Dusinska, M.; Hemminki, K.; Vodicka, P. Genetic polymorphisms and possible gene-gene interactions in metabolic and DNA repair genes: Effects on DNA damage. Mutat. Res. 2006, 593, 22-31. [CrossRef] [PubMed]

21. Pavanello, S.; Pulliero, A.; Siwinska, E.; Mielzynska, D.; Clonfero, E. Reduced nucleotide excision repair and GSTM1-null genotypes influence anti-B[a]pde-DNA adduct levels in mononuclear white blood cells of highly PAH-exposed coke oven workers. Carcinogenesis 2005, 26, 169-175. [CrossRef] [PubMed]

22. Engin, A.B.; Karahalil, B.; Engin, A.; Karakaya, A.E. Oxidative stress, Helicobacter pylori, and OGG1 Ser326Cys, XPC Lys939Gln, and XPD Lys751Gln polymorphisms in a Turkish population with colorectal carcinoma. Genet. Test. Mol. Biomark. 2010, 14, 559-564. [CrossRef] [PubMed]

23. Gil, J.; Ramsey, D.; Stembalska, A.; Karpinski, P.; Pesz, K.A.; Laczmanska, I.; Leszczynski, P.; Grzebieniak, Z.; Sasiadek, M.M. The C/A polymorphism in intron 11 of the XPC gene plays a crucial role in the modulation of an individual's susceptibility to sporadic colorectal cancer. Mol. Biol. Rep. 2012, 39, 527-534. [CrossRef] [PubMed]

24. Hansen, R.D.; Sorensen, M.; Tjonneland, A.; Overvad, K.; Wallin, H.; Raaschou-Nielsen, O.; Vogel, U. XPA A23G, XPC Lys939Gln, XPD Lys751Gln and XPD Asp312Asn polymorphisms, interactions with smoking, alcohol and dietary factors, and risk of colorectal cancer. Mutat. Res. 2007, 619, 68-80. [CrossRef] [PubMed]

25. Huang, W.Y.; Berndt, S.I.; Kang, D.; Chatterjee, N.; Chanock, S.J.; Yeager, M.; Welch, R.; Bresalier, R.S.; Weissfeld, J.L.; Hayes, R.B. Nucleotide excision repair gene polymorphisms and risk of advanced colorectal adenoma: XPC polymorphisms modify smoking-related risk. Cancer Epidemiol. Biomark. Prev. 2006, 15, 306-311. [CrossRef] [PubMed]

26. Pardini, B.; Naccarati, A.; Novotny, J.; Smerhovsky, Z.; Vodickova, L.; Polakova, V.; Hanova, M.; Slyskova, J.; Tulupova, E.; Kumar, R.; et al. DNA repair genetic polymorphisms and risk of colorectal cancer in the Czech Republic. Mutat. Res. 2008, 638, 146-153. [CrossRef] [PubMed]

27. Paszkowska-Szczur, K.; Scott, R.J.; Gorski, B.; Cybulski, C.; Kurzawski, G.; Dymerska, D.; Gupta, S.; van de Wetering, T.; Masojc, B.; Kashyap, A.; et al. Polymorphisms in nucleotide excision repair genes and susceptibility to colorectal cancer in the Polish population. Mol. Biol. Rep. 2015, 42, 755-764. [CrossRef] [PubMed]

28. Steck, S.E.; Butler, L.M.; Keku, T.; Antwi, S.; Galanko, J.; Sandler, R.S.; Hu, J.J. Nucleotide excision repair gene polymorphisms, meat intake and colon cancer risk. Mutat. Res. 2014, 762, 24-31. [CrossRef] [PubMed]

29. Wu, Y.; Jin, M.; Liu, B.; Liang, X.; Yu, Y.; Li, Q.; Ma, X.; Yao, K.; Chen, K. The association of XPC polymorphisms and tea drinking with colorectal cancer risk in a Chinese population. Mol. Carcinog. 2011, 50, 189-198. [CrossRef] [PubMed]

30. Yue, A.M.; Xie, Z.B.; Zhao, H.F.; Guo, S.P.; Shen, Y.H.; Wang, H.P. Associations of $A B C D 1$ and XPC genetic polymorphisms with susceptibility to colorectal cancer and therapeutic prognosis in a Chinese population. Asian Pac. J. Cancer Prev. 2013, 14, 3085-3091. [CrossRef] [PubMed]

31. Wang, G.; Sun, H.; Liu, Z.; Huang, R.; Chen, Y.; Tang, Q.; Yu, L.; Jiang, Z.; Wang, X. Lack of associations between XPC polymorphisms and colorectal cancer: A meta-analysis. J. BUON 2015, 20, 770-774. [PubMed]

32. Ke, J.; Lou, J.; Chen, X.; Li, J.; Liu, C.; Gong, Y.; Yang, Y.; Zhu, Y.; Zhang, Y.; Tian, J.; et al. Identification of a functional variant for colorectal cancer risk mapping to chromosome 5q31.1. Oncotarget 2016, 7, 35199-35207. [CrossRef] [PubMed]

33. He, J.; Qiu, L.X.; Wang, M.Y.; Hua, R.X.; Zhang, R.X.; Yu, H.P.; Wang, Y.N.; Sun, M.H.; Zhou, X.Y.; Yang, Y.J.; et al. Polymorphisms in the XPG gene and risk of gastric cancer in Chinese populations. Hum. Genet. 2012, 131, 1235-1244. [CrossRef] [PubMed]

34. Zhu, J.; Wang, M.; Zhu, M.; He, J.; Wang, J.C.; Jin, L.; Wang, X.F.; Xiang, J.Q.; Wei, Q. Associations of PI3KR1 and mTOR polymorphisms with esophageal squamous cell carcinoma risk and gene-environment interactions in Eastern Chinese populations. Sci. Rep. 2015, 5, 8250. [CrossRef] [PubMed]

35. Zhu, J.; Wang, M.; He, J.; Zhu, M.; Wang, J.C.; Jin, L.; Wang, X.F.; Yang, Y.J.; Xiang, J.Q.; Wei, Q. Polymorphisms in the $A K T 1$ and $A K T 2$ genes and oesophageal squamous cell carcinoma risk in an Eastern Chinese population. J. Cell. Mol. Med. 2016, 20, 666-677. [CrossRef] [PubMed]

36. Moher, D.; Liberati, A.; Tetzlaff, J.; Altman, D.G. Preferred reporting items for systematic reviews and meta-analyses: The PRISMA statement. PLoS Med. 2009, 6, e1000097. [CrossRef] [PubMed] 
37. Zhu, J.; Hua, R.X.; Jiang, J.; Zhao, L.Q.; Sun, X.; Luan, J.; Lang, Y.; Sun, Y.; Shang, K.; Peng, S.; et al. Association studies of ERCC1 polymorphisms with lung cancer susceptibility: A systematic review and meta-analysis. PLoS ONE 2014, 9, e97616. [CrossRef] [PubMed]

38. He, J.; Liao, X.Y.; Zhu, J.H.; Xue, W.Q.; Shen, G.P.; Huang, S.Y.; Chen, W.; Jia, W.H. Association of mTHFRC677T and A1298C polymorphisms with non-Hodgkin lymphoma susceptibility: Evidence from a meta-analysis. Sci. Rep. 2014, 4, 6159. [CrossRef] [PubMed]

39. Xie, S.; Shan, X.F.; Shang, K.; Xu, H.; He, J.; Cai, Z.G. Relevance of LIG4 gene polymorphisms with cancer susceptibility: Evidence from a meta-analysis. Sci. Rep. 2014, 4, 6630. [CrossRef] [PubMed]

40. Hua, R.X.; Li, H.P.; Liang, Y.B.; Zhu, J.H.; Zhang, B.; Ye, S.; Dai, Q.S.; Xiong, S.Q.; Gu, Y.; Sun, X.Z. Association between the PARP1 Val762Ala polymorphism and cancer risk: Evidence from 43 studies. PLoS ONE 2014, 9, e87057. [CrossRef] [PubMed]

(C) 2016 by the authors; licensee MDPI, Basel, Switzerland. This article is an open access article distributed under the terms and conditions of the Creative Commons Attribution (CC-BY) license (http://creativecommons.org/licenses/by/4.0/). 